\title{
KEJADIAN STAGNANT DAN STOCKOUT OBAT KARDIOVASKULER DI INSTALASI FARMASI RUMAH SAKIT
}

\author{
${ }^{1}$ Sekolah Tinggi Ilmu Farmasi Nusaputera, Semarang, Indonesia \\ *corresponding author \\ Email: eleonorareth@gmail.com
}

Eleonora Maryeta Toyo ${ }^{*}$, Sri Suwarni ${ }^{1}$, Yolanda Ernidiasanti ${ }^{1}$

Diterima : 09 September 2021

Direvisi : 01 Oktober 2021

Publikasi : 20 Oktober 2021

doi:10.52216/jfsi.vol4no2p41-49

\begin{abstract}
Drug management is carried out as an effort to control drug inventory in hospital pharmacy installations to know the incidence of stagnant and stockout of cardiovascular drugs from the internal medicine specialist poly. This research was conducted in March-April 2021, with a cross-sectional study design with retrospective data search. The data instrument used is an electronic stock card specifically for the use of cardiovascular drugs in hospital outpatient installations, including; antianginal, antidyslipidemic, antihypertensive, and antiplatelet drugs. The number of samples used was 50 items of cardiovascular drugs. Data processing is carried out qualitatively and quantitatively. The results showed that the highest number was found in the antihypertensive therapy class as many as 32 items with an amount of stagnant $12 \%$ and a total stockout of $31.3 \%$.
\end{abstract}

Keywords: Cardiovascular Medicine, Stagnant, Stockout, Hospital

\section{Intisari}

Manajemen pengelolan obat dilakukan sebagai upaya dalam pengendalian persediaan obat di instalasi farmasi rumah sakit dengan tujuan untuk mengetahui kejadian stagnant dan stockout obat kardiovaskuler dari poli spesialis penyakit dalam. Penelitian ini dilakukan pada bulan Maret-April tahun 2021, dengan rancangan cross sectional study dengan penelusuran data secara retrospektif. Instrumen data yang digunakan adalah kartu stok elektronik khusus panggunaan obat-obat kardiovaskuler yang ada di instalasi rawat jalan rumah sakit, meliputi; obat antiangina, antidislipidemia, antihipertensi dan antiplatelet. Jumlah sampel yang digunakan 50 item obat kardiovaskuler. Pengolahan data dilakukan secara kualitatif dan kuantitatif. Hasil penelitian menunjukkan bahwa jumlah tertinggi terdapat pada kelas terapi antihipertensi sebanyak 32 item dengan jumlah stagnant $12 \%$ dan jumlah stockout $31,3 \%$.

Kata kunci: Obat Kardiovaskuler, Stagnant, Stockout, Rumah Sakit

\section{Pendahuluan}

Pelayanan kesehatan merupakan upaya yang dilakukan secara individu maupun bersama dalam satu organisasi dengan tujuan untuk meningkatkan kesehatan perseorangan, keluarga, dan masyarakat
(Ali et al., 2017). Pelayanan di rumah sakit tidak terlepas dari pengelolaan perbekalan farmasi yang meliputi obat-obatan, bahan kimia, bahan radiologi, alat kesehatan habis pakai, alat-alat kedokteran dan gas medik (Pebrianti, n.d. 2015). 
Standar pelayanan kefarmasian merupakan tolak ukur yang digunakan sebagai pedoman bagi tenaga kefarmasian dalam menyelenggarakan pelayanan kefarmasian. Salah satu sediaan farmasi yang didistribusikan dalam pelayanan kesehatan yaitu obat. Obat merupakan bahan atau paduan bahan termasuk produk biologi yang digunakan untuk mempengaruhi atau menyelidiki sistem fisiologi atau keadaan patologi dalam rangka penetapan diagnosis, pencegahan, penyembuhan, pemulihan, peningkatan kesehatan, dan kontrasepsi untuk manusia (Cahya, 2016).

Ketersediaan obat di rumah sakit sangat mempengaruhi keberhasilan pengobatan dan kualitas pelayanan, sehingga rumah sakit harus memiliki sediaan farmasi yang cukup memadai dari segi kualitas dan kuantitas. Hal tersebut guna mencapai peranan rumah sakit dalam meningkatkan derajat kesehatan masyarakat yang dipengaruhi oleh manajemen pengelolaan sediaan farmasi. Pengelolaan sediaan farmasi di rumah sakit merupakan bagian dari manajemen rumah sakit yang bertujuan agar obat yang diperlukan tersedia setiap saat, jumlah ketersediaannya cukup, dan terjamin kualitasnya.

Manajemen pengelolaan sediaan farmasi adalah bagian dari manajemen logistik yang melewati beberapa siklus yaitu; pemilihan, perencanaan kebutuhan, pengadaan, penerimaan, penyimpanan, pendistribusian, pemusanahan dan penarikan, pengendalian dan administrasi sediaan farmasi, alat kesehatan dan bahan medis habis pakai (Cahya, 2016a). Tahap perencanaan merupakan dasar pengelolaan sediaan farmasi untuk melanjutkan ke tahap berikut, sehingga diperlukan pengetahuan dan ketelitian yang baik agar tidak terjadi kesalahan dalam memperhitungkan ketersediaan farmasi di rumah saki (Suciati, 2006). Jika sistem manajemen pengelolaan sediaan farmasi buruk, maka akan berdampak pada kualitas pelayanan rumah sakit. Oleh karena itu, dibutuhkan manajemen pengelolaan yang sesuai dengan standar operasional prosedur (SOP) sebagai pedoman dalam pelaksanaan kegiatan pengelolaan sediaan farmasi (Laidahane, 2018). Manajemen obat yang kurang baik akan menyebabkan persediaan obat mengalami stagnant (kelebihan persediaan obat) dan stockout (kekurangan atau kekosongan persediaan obat). Obat yang mengalami kejadian stagnant memiliki risiko kadaluwarsa dan kerusakan bila tidak disimpan dengan baik, sedangkan jika terjadi stockout maka akan menyebabkan pasien merasa tidak puas dan rumah sakit akan kehilangan kesempatan untuk mendapatkan keuntungan (Seto et al., 2015).

Data yang diperoleh dari riset kesehatan dasar (Riskesdas) menunjukkan bahwa adanya kenaikan jumlah penduduk yang menderita strok dan hipertensi sehingga kebutuhan pengobatannya meningkat (Indrawati \& Tjandrarini, 2018). Hal tersebut menyatakan bahwa penyakit strok, jantung iskemik, dan hipertensi termasuk dalam sepuluh besar penyakit mematikan di Indonesia (Indonesia, 2014). Pengobatan yang digunakan tidak hanya mengurangi keluhan, melainkan mampu memelihara fungsi jantung sehingga dapat meningkatkan kualitas hidup pasien. Pasien yang mengalami komplikasi dapat mengonsumsi berbagai macam obat (Yahya \& Sp JP K, 2010). Prevalensi tersebut mempunyai hubungan erat dalam siklus manajemen obat di rumah sakit.

Rumah sakit yang menjadi lokasi penelitian ini merupakan rumah sakit umum swasta kelas C. Rumah sakit tersebut memiliki fasilitas dan kemampuan pelayanan medik. Pada pelayanan rawat jalan tepatnya poli penyakit dalam, jumlah kunjungan pasien bertambah banyak. Hal ini berpengaruh pada ketersediaan obat yang ada di rumah sakit, terutama kebutuhan obat-obatan kardiovaskuler. Oleh karena itu, dibutuhkan bahan evaluasi dalam perhitungan kejadian stagnant dan stockout obat kardiovaskuler agar tidak terjadi kekosongan atau kelebihan persediaan obat di rumah sakit.

\section{Metode Penelitian}

Penelitian ini menggunakan rancangan cross sectional study dengan penelusuran data secara retrospektif. Instrumen data yang digunakan adalah kartu stok elektronik khusus panggunaan obat-obat kardiovaskuler yang ada di instalasi rawat jalan rumah sakit, meliputi; obat antiangina, antidislipidemia, antihipertensi dan antiplatelet. Keterangan lain yang digunakan adalah nama obat, stok awal, jumlah penerimaan dan pengeluaran obat, jumlah sisa obat pada akhir bulan Oktober-Desember 2020, serta keterangan stagnant dan stockout. Teknik pengambilan sampel menggunakan teknik jenuh, dimana 
sampel yang digunakan berasal dari semua populasi (Rangkuti, 2014). Jumlah sampel yang digunakan adalah 50 item obat kardiovaskuler.

Pengolahan data dilakukan secara kualitatif dan kuantitatif. Kualitatif dengan menggambarkan daftar obat-obat kardiovaskuler yang mengalami stagnant dan stockout di rumah sakit. Sedangkan kuantitatif menghitung jumlah obat kardiovaskuler yang mengalami stagnant dan stockout, kemudian disajikan dalam bentuk persentase.

Berikut rumus dalam perhitungan stagnant dan stockout mengacu pada rumus persentase oleh Anas Sudijono (Anas, 2008).

a) Perhitungan stagnant tiap bulan

Jumlah item obat stagnant $\times 100 \%$

Jumlah obat kardiovaskuler

b) Perhitungan stockout tiap bulan

Jumlah item obat stockout $\quad$ x $100 \%$

Jumlah obat kardiovaskuler

Selanjutnya dilakukan perhitungan stagnant dan stockout pada bulan Oktober-Desember 2020, sebagai berikut;

\section{1) Stagnant}

Stagnant oktober + stagnant november+stagnant desember 3

\section{2) Stockout}

$\underline{\text { Stockout } \text { oktober }+ \text { stockout november }+ \text { stockout desember }}$ 3

\section{Hasil dan Pembahasan}

\subsection{Obat Kardiovaskuler}

Obat kardiovaskuler yang terdapat di instalasi farmasi rawat jalan rumah sakit, dikelompokkan menjadi 4 macam kelas terapi yang dapat dilihat pada tabel 1 . Terdapat berbagai macam obat yang sering diresepkan oleh dokter spesialis penyakit dalam.

Hipertensi disebut dengan the silent desease atau penyakit tersembunyi, yang merupakan suatu keadaan tanpa gejala, dimana tekanan darah tinggi menyebabkan peningkatan risiko terhadap penyakit-penyakit kardiovaskuler seperti stroke, gagal jantung, serangan jantung, kerusakan ginjal (Elvira \& Anggraini, 2019). Faktor-faktor pencetus timbulnya hipertensi di antaranya; merokok, kekurangan berolahraga, obesitas, jenis kelamin, asupan garam berlebih, alkohol, kafein, faktor genetik, usia, dan tinggi kolesterol (Susilo Yekti, 2012). Hal ini menunjukkan bahwa jumlah penggunaan obat antihipertensi sebesar $64 \%$. Artinya; banyak pasien yang menggunakan obat tersebut untuk mengatasi gejala-gejala hipertensi. Target utama pengobatan antihipertensi ini adalah untuk mempertahankan tekanan darah pada rantang normal, sehingga dapat menurunkan morbiditas dan mortalitas komplikasi kardiovaskuler (Karo, 2012).

Antiplatelet merupakan salah satu terapi yang diberikan kepada penderita stroke iskemik sebesar $16 \%$. Hal ini disebabkan oleh disfungsi atau kerusakan jaringan, dimana berkurangnya aliran darah ke otak sehingga mengganggu kebutuhan darah dan oksigen di otak (Kabi et al., 2015). Faktor risiko yang menyebabkan terjadinya stroke iskemik, di antaranya; hipertensi, diabetes melitus, dan dislipidemia (Siti Rohmatul Laily, 2017). Selanjutnya penggunaan dislipidemia sebesar $12 \%$, dimana penyakit ini merupakan kelainan metabolisme lipid yang ditandai dengan peningkatan atau penurunan profil lipid dalam plasma darah. Kelainan profil lipid yang paling utama adalah kenaikan kadar kolesterol total, kolesterol LDL, kenaikan kadar trigliserida serta penurunan kadar HDL (Anwar \& Bahri, 2004).

Antiangina merupakan terapi yang diberikan pada pasien dengan nyeri dada yang mendadak akibat ketidakseimbangan antara aliran darah koroner dengan kebutuhan $\mathrm{O}_{2}$ miokard. Hal tersebut menunjukkan bahwa angka morbiditas pasien yang melakukan pengobatan antiangina di rawat jalan di rumah sakit sebesar $8 \%$. Nyeri dada atau rasa tidak nyaman di dada merupakan gejala utama dan yang paling banyak dikeluhkan oleh pasien sindrom koroner akut yang berobat di rumah sakit (Ridwan et al., 2020). 
Tabel 1. Pengelompokan Obat Kardiovaskuler

\begin{tabular}{|c|c|c|c|c|c|}
\hline No & Kelas Terapi & Jenis & Nama Obat & Jumlah & Persentase (\%) \\
\hline \multirow{2}{*}{1.} & \multirow{2}{*}{ Antiangina } & Vasodilator Koroner & $\begin{array}{l}\text { Isosorbide dinitrat } 5 \mathrm{mg} \\
\text { Nitrokaf Retard cap }\end{array}$ & \multirow{2}{*}{4 item } & \multirow{2}{*}{8} \\
\hline & & & $\begin{array}{l}\text { Coralan } 5 \mathrm{mg} \text { tab } \\
\text { Trizedon MR tab }\end{array}$ & & \\
\hline
\end{tabular}

Fibrat

2. Antidislipidemia Statin
Fenofibrate $300 \mathrm{mg}$ cap

Gemfibrozil 300 mg cap

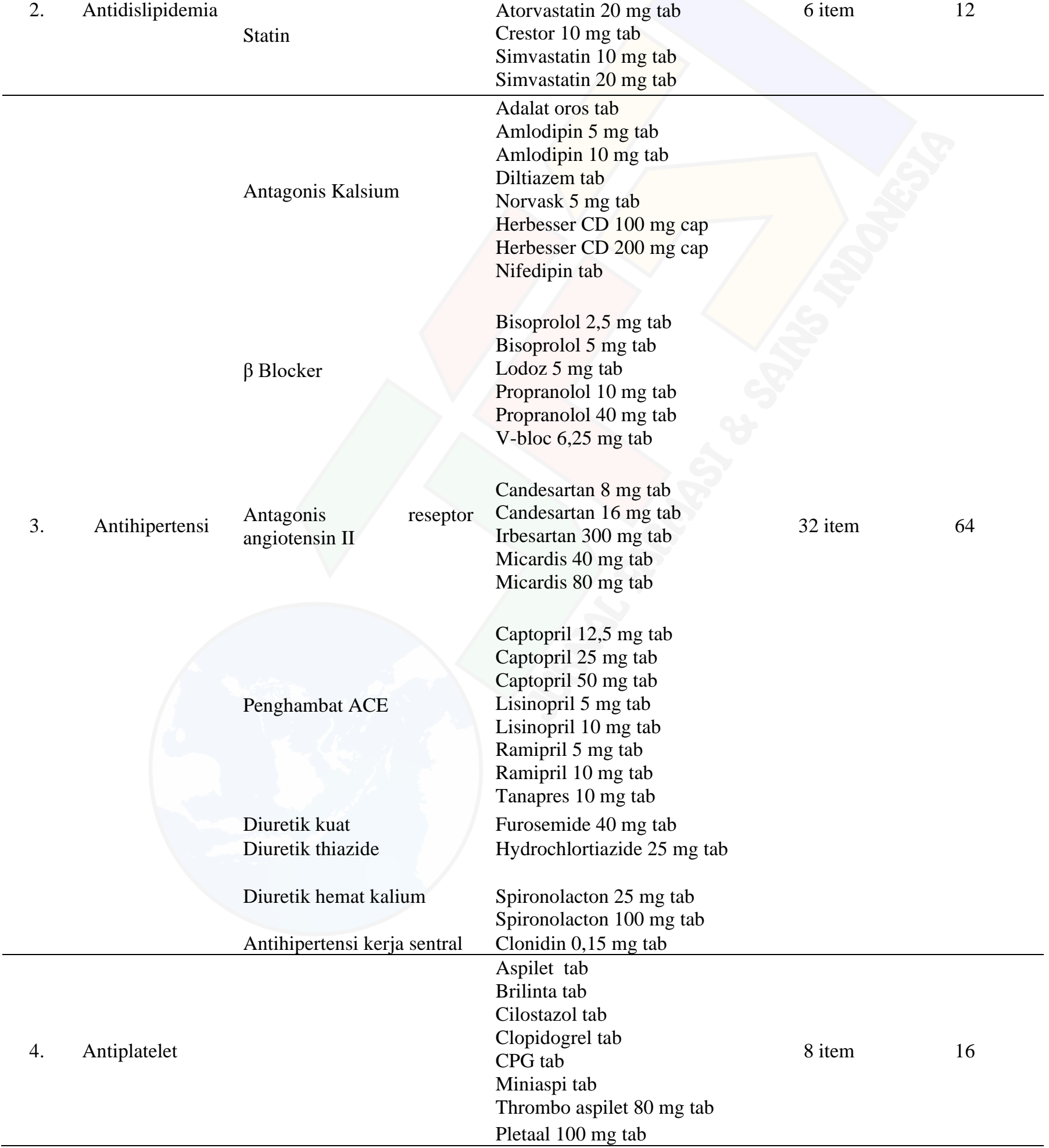


Tabel 2. Kejadian Stagnant Dan Stockout Obat Kardiovaskuler

\begin{tabular}{|c|c|c|c|c|c|c|}
\hline \multirow[b]{2}{*}{ No } & \multirow[b]{2}{*}{ Kelas Terapi } & \multirow[b]{2}{*}{ Jenis } & \multirow[b]{2}{*}{ Nama Obat } & \multirow[b]{2}{*}{ Jumlah } & \multicolumn{2}{|c|}{ Persentase $(\%)$} \\
\hline & & & & & $\begin{array}{l}\text { Kejadian } \\
\text { Stagnant }\end{array}$ & $\begin{array}{l}\text { Kejadian } \\
\text { Stockout }\end{array}$ \\
\hline 1. & Antiangina & $\begin{array}{l}\text { Vasodilator } \\
\text { Koroner }\end{array}$ & $\begin{array}{l}\text { Isosorbide dinitrat } 5 \mathrm{mg} \text { tab } \\
\text { Nitrokaf Retard cap } \\
\text { Coralan } 5 \mathrm{mg} \text { tab } \\
\text { Trizedon MR tab }\end{array}$ & 4 item & 4 & 2 \\
\hline & & Fibrat & $\begin{array}{l}\text { Fenofibrate } 300 \mathrm{mg} \text { cap } \\
\text { Gemfibrozil } 300 \mathrm{mg} \text { cap }\end{array}$ & & & \\
\hline 2. & Antidislipidemia & Statin & $\begin{array}{l}\text { Atorvastatin } 20 \mathrm{mg} \text { tab } \\
\text { Crestor } 10 \mathrm{mg} \mathrm{tab} \\
\text { Simvastatin } 10 \mathrm{mg} \text { tab } \\
\text { Simvastatin } 20 \mathrm{mg} \mathrm{tab}\end{array}$ & 6 it & 3,3 & 3,3 \\
\hline & & $\begin{array}{l}\text { Antagonis } \\
\text { Kalsium }\end{array}$ & $\begin{array}{l}\text { Adalat oros tab } \\
\text { Amlodipin } 5 \mathrm{mg} \mathrm{tab} \\
\text { Amlodipin } 10 \mathrm{mg} \mathrm{tab} \\
\text { Diltiazem tab } \\
\text { Herbesser CD } 100 \mathrm{mg} \text { cap } \\
\text { Herbesser CD } 200 \mathrm{mg} \text { cap } \\
\text { Nifedipin tab } \\
\text { Norvask } 5 \mathrm{mg} \text { tab }\end{array}$ & & & \\
\hline & & $\beta$ Blocker & $\begin{array}{l}\text { Bisoprolol } 2,5 \mathrm{mg} \text { tab } \\
\text { Bisoprolol } 5 \mathrm{mg} \text { tab } \\
\text { Lodoz } 5 \mathrm{mg} \mathrm{tab} \\
\text { Propranolol } 10 \mathrm{mg} \text { tab } \\
\text { Propranolol } 40 \mathrm{mg} \mathrm{tab} \\
\text { V-bloc } 6,25 \mathrm{mg} \mathrm{tab}\end{array}$ & & & \\
\hline 3. & Antihipertensi & $\begin{array}{l}\text { Antagonis } \\
\text { reseptor } \\
\text { angiotensin II }\end{array}$ & $\begin{array}{l}\text { Candesartan } 8 \mathrm{mg} \text { tab Candesartan } \\
16 \mathrm{mg} \text { tab } \\
\text { Irbesartan } 300 \mathrm{mg} \text { tab } \\
\text { Micardis } 40 \mathrm{mg} \text { tab } \\
\text { Micardis } 80 \mathrm{mg} \text { tab }\end{array}$ & 32 item & 12 & 31,3 \\
\hline & & $\begin{array}{l}\text { Penghambat } \\
\text { ACE }\end{array}$ & $\begin{array}{l}\text { Captopril } 12,5 \mathrm{mg} \text { tab } \\
\text { Captopril } 25 \mathrm{mg} \mathrm{tab} \\
\text { Captopril } 50 \mathrm{mg} \mathrm{tab} \\
\text { Lisinopril } 5 \mathrm{mg} \mathrm{tab} \\
\text { Lisinopril } 10 \mathrm{mg} \mathrm{tab} \\
\text { Ramipril } 5 \mathrm{mg} \mathrm{tab} \\
\text { Ramipril } 10 \mathrm{mg} \mathrm{tab} \\
\text { Tanapres } 10 \mathrm{mg} \mathrm{tab}\end{array}$ & & & \\
\hline & & $\begin{array}{l}\text { Diuretik kuat } \\
\text { Diuretik } \\
\text { thiazide }\end{array}$ & $\begin{array}{l}\text { Furosemide } 40 \mathrm{mg} \text { tab } \\
\text { Hydrochlorothiazide } 25 \mathrm{mg} \text { tab }\end{array}$ & & & \\
\hline & & $\begin{array}{l}\text { Diuretik hemat } \\
\text { kalium }\end{array}$ & $\begin{array}{l}\text { Spironolacton } 25 \mathrm{mg} \text { tab } \\
\text { Spironolacton } 100 \mathrm{mg} \text { tab }\end{array}$ & & & \\
\hline & & $\begin{array}{l}\text { Antihipertensi } \\
\text { kerja sentral }\end{array}$ & Clonidin $0,15 \mathrm{mg}$ tab & & & \\
\hline 4. & Antiplatelet & & $\begin{array}{l}\text { Aspilet tab } \\
\text { Brilinta tab } \\
\text { Cilostazol tab } \\
\text { Clopidogrel tab } \\
\text { CPG tab } \\
\text { Miniaspi tab } \\
\text { Pletaal } 100 \mathrm{mg} \mathrm{tab} \\
\text { Thrombo Aspilet } 80 \mathrm{mg} \mathrm{tab}\end{array}$ & 8 item & 6,7 & 2,7 \\
\hline
\end{tabular}


3.2. Kejadian Stagnant Dan Stockout Obat Kardiovaskuler

Kejadian stagnant dan stockout dapat disebabkan oleh perencanaan dan pengadaan obat yang berlebihan serta tidak akurat. Selain itu karena adanya perubahan pola penyakit, sehingga obat yang telah direncanakan berdasarkan pemakaian sebelumnya tidak sesuai dengan kebutuhan. Oleh sebab itu dibutuhkan manajemen perencanaan dan pengadaan obat yang baik dan benar (Mellen \& Pudjirahardjo, 2013). Stagnant dan stockout yang sering terjadi dapat juga dipengaruhi oleh metode penyimpanan obat dengan metode First Expired First Out (FEFO) dan First In First Out (FIFO). Prinsip bahwa perbekalan sediaan farmasi yang datang lebih awal harus digunakan segera, sebab pada umumnya diproduksi lebih awal dan masa kadaluwarsa lebih cepat. Hal ini dapat memudahkan petugas farmasi dalam mengatur siklus obat masuk maupun obat keluar sehingga tidak terjadi stagnant dan stockout pada gudang penyimpanan (Laidahane, 2018). Hasil perhitungan kejadian stagnant dan stockout dapat dilihat pada tabel 2 dan total kejadian stagnant dan stokout obat kardiovaskular dapat dilihat pada tabel 3.

Berdasarkan tabel 2 menunjukkan bahwa kejadian stagnant dan stockout tertinggi adalah kelas terapi penggunaan obat antihipertensi. Menurut JNC 7 terapi hipertensi dilakukan dengan mendapatkan pengobatan dalam interval satu bulan sampai tekanan darah yang diinginkan tercapai. Jika tekanan darah tersebut sudah tercapai dan stabil, kunjungan selanjutnya dapat dilakukan dalam interval waktu 3-6 bulan (Education et al., 2003). Hal ini dipengaruhi oleh karakteristik dokter dan tenaga kefarmasian, pedoman pengobatan hipertensi, resep dokter, frekuensi kunjungan, ketersediaan obat antihipertensi dan jumlah obat antihipertensi yang diterima pasien hipertensi terhadap jumlah jenis dan jumlah obat antihipertensi untuk pasien hipertensi (Lionetto et al., 2020). Selain itu, sebagian besar jumlah obat antihipertensi yang diberikan kepada pasien hipertensi tidak sesuai dengan yang tertulis di resep dokter karena ketersediaan obat antihipertensi kurang dari kebutuhan obat pasien hipertensi. Faktor lain yang mempengaruhi kejadian stagnant dan stockout ini adalah dokter dalam melakukan pola peresepan akan ketersediaan obat yang ada di rumah sakit. Pola peresepan bervariasi sehingga mempengaruhi ketersediaan obat dan menyebabkan obat0bat yang digunakan berubah akibat banyaknya obat yang tidak keluar atau tidak digunakan dan menumpuk (Huda et al., 2020).

Ketersediaan obat antihipertensi di rumah sakit pun mengalami kekurangan dari jumlah kebutuhan obat antihipertensi, sehingga pasien hanya menerima obat-obat tertentu saja. Solusi untuk meningkatkan ketersediaan obat yaitu dengan meningkatkan keterampilan manajemen pengelolaan perbekalan sediaan farmasi, terutama dengan menghitung kebutuhan jenis dan jumlah obat yang ada di rumah sakit (Herlina, 2020). Hal tersebut dapat dilakukan dengan menggunakan metode off the job training, karena metode ini terbukti efektif dalam meningkatkan pengetahuan dan keterampilan pengelolaan obat yang meliputi perencanaan dan analisis kebutuhan jenis dan jumlah obat (Carolien et al., 2017). Waktu pemberian obat antihipertensi di rumah sakit kurang lebih 10 hari. Artinya bahwa masa penggunaan obat antihipertensi tidak sesuai dengan Permenkes no. 5 tahun 2014 dan JNC 7 bahwa terapi penggunaan obat tersebut selama 2 minggu atau 1 bulan untuk mengoptimalkan hasil pengobatan sampai tekanan darah yang diinginkan tercapai. Hal ini akan berpengaruh pada frekuensi kunjungan pasien ke rumah sakit yang dapat dilakukan sebanyak 3 kali dalam sebulan (Darnindro \& Sarwono, 2017).

Administrasi di rumah sakit termasuk dalam pencatatan yang belum dilakukan dengan optimal karena hanya terdapat 4 apoteker dan 12 tenaga teknis kefarmasian sehingga waktu untuk melakukan administrasi pengelolaan obat dan peningkatan mutu pelayanan obat berkurang. Berdasarkan Permenkes no. 30 tahun 2019 tentang klasifikasi dan perizinan rumah sakit rumah sakit, untuk kebutuhan beban kerja pelayanan kefarmasian kelas $\mathrm{C}$ yaitu apoteker 6 dan tenaga teknis kefarmasian 8, sedangkan dalam sehari rumah sakit menerima pasien rawat jalan sekitar 500-700 orang. Artinya ada perbandingan yang nyata antara tenaga kefarmasian dan frekuensi kunjungan pasien yang dapat menyebabkan terjadinya beberapa kesalahan yang menyebabkan administrasi pengelolaan obat menjadi berkurang. 
Tabel 3. Total Kejadian Stagnant dan Stokout Obat Kardiovaskular

Tabel 3. Total Kejadian Stagnant
Kelas

\section{Terapi}

\begin{tabular}{|c|c|c|c|c|c|c|c|}
\hline & & & \\
\hline & & Stagnant & Stockout & Stagnant & Stockout & Stagnant & Stockout \\
\hline \multirow{5}{*}{ Anti Angina } & Coralan $5 \mathrm{mg}$ tab & $\checkmark$ & & $\checkmark$ & & & \\
\hline & Isosorbid Dinitrate tab & & $\checkmark$ & & $\checkmark$ & $\checkmark$ & \\
\hline & Nitrokaf Retard cap & & $\checkmark$ & $\checkmark$ & & $\checkmark$ & \\
\hline & Trizedon MR tab & $\checkmark$ & & & & & \\
\hline & Total & 2 & 2 & 2 & 1 & 2 & $\mathbf{0}$ \\
\hline \multirow{7}{*}{$\begin{array}{c}\text { Anti } \\
\text { Dislipidemia }\end{array}$} & Atorvastatin $20 \mathrm{mg}$ tab & & & $\checkmark$ & & $\checkmark$ & \\
\hline & Crestor $10 \mathrm{mg}$ tab & $\checkmark$ & & $\checkmark$ & & $\checkmark$ & \\
\hline & Fenofibrate $300 \mathrm{mg}$ cap & & $\checkmark$ & & $\checkmark$ & 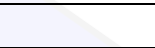 & \\
\hline & Gemfibrozil 300 mg cap & & $\checkmark$ & 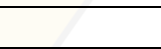 & $\checkmark$ & 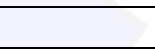 & $\checkmark$ \\
\hline & Simvastatin $10 \mathrm{mg}$ tab & & 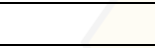 & & & 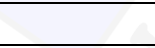 & 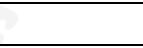 \\
\hline & Simvastatin $20 \mathrm{mg}$ tab & & - & 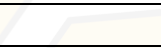 & & +2 & \\
\hline & Total & 1 & 2 & 2 & 2 & 2 & 1 \\
\hline \multirow{27}{*}{ Anti Hipertensi } & Adalat Oros $30 \mathrm{mg}$ tab & & $\checkmark$ & & $\checkmark$ & +3 & $\checkmark$ \\
\hline & Amlodipin $5 \mathrm{mg}$ tab & & & & & & \\
\hline & Amlodipin $10 \mathrm{mg}$ tab & & $\checkmark$ & 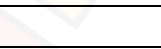 & $\checkmark$ & & $\checkmark$ \\
\hline & Bisoprolol 2,5 mg tab & & $\checkmark$ & & $\checkmark$ & 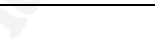 & $\checkmark$ \\
\hline & Bisoprolol $5 \mathrm{mg}$ tab & & $\checkmark$ & & $\checkmark$ & & \\
\hline & Candesartan $8 \mathrm{mg}$ tab & & & $\checkmark$ & +2 & $\checkmark$ & \\
\hline & Candesartan $16 \mathrm{mg}$ tab & 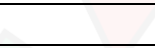 & $\checkmark$ & & +2 & & \\
\hline & Captopril $12,5 \mathrm{mg}$ tab & $\checkmark$ & & $\checkmark$ & 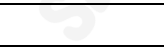 & $\checkmark$ & \\
\hline & Captopril $25 \mathrm{mg}$ tab & 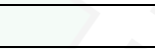 & $\checkmark$ & & $\checkmark$ & & $\checkmark$ \\
\hline & Captopril $50 \mathrm{mg}$ tab & 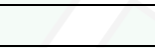 & $\checkmark$ & & $\checkmark$ & & $\checkmark$ \\
\hline & Clonidin tab & 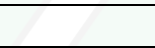 & $\checkmark$ & 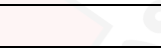 & $\checkmark$ & & $\checkmark$ \\
\hline & Diltiazem tab & $\bar{x}$ & $\checkmark$ & 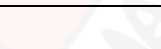 & $\checkmark$ & & $\checkmark$ \\
\hline & Furosemide tab & & $\checkmark$ & 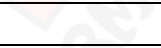 & $\checkmark$ & & $\checkmark$ \\
\hline & $\begin{array}{l}\text { Herbesser CD } 100 \mathrm{mg} \\
\text { cap }\end{array}$ & & & (2) & & & \\
\hline & $\begin{array}{l}\text { Herbesser CD } 200 \mathrm{mg} \\
\text { cap }\end{array}$ & & $\checkmark$ & 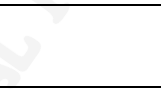 & & $\checkmark$ & \\
\hline & Hydrochlorotiazide & 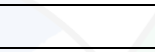 & $\checkmark$ & & $\checkmark$ & & $\checkmark$ \\
\hline & Irbesartan $300 \mathrm{mg}$ tab & $\checkmark$ & 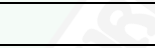 & $\checkmark$ & & & $\checkmark$ \\
\hline & Lisinopril $5 \mathrm{mg}$ tab & & $\checkmark$ & & & & \\
\hline & Lisinopril $10 \mathrm{mg}$ tab & 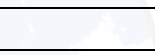 & $\checkmark$ & & $\checkmark$ & & $\checkmark$ \\
\hline & Lodoz $5 \mathrm{mg}$ tab & $\checkmark$ & & $\checkmark$ & & $\checkmark$ & \\
\hline & Micardis $40 \mathrm{mg}$ tab & $\checkmark$ & & & & & \\
\hline & Micardis $80 \mathrm{mg}$ tab & & & & $\checkmark$ & & \\
\hline & Nifedipin $10 \mathrm{mg}$ tab & $\checkmark$ & & $\checkmark$ & & $\checkmark$ & \\
\hline & Norvask $5 \mathrm{mg} \mathrm{tab}$ & & & & $\checkmark$ & & \\
\hline & Propranolol $10 \mathrm{mg}$ tab & 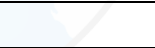 & $\checkmark$ & & $\checkmark$ & & $\checkmark$ \\
\hline & Propranolol $40 \mathrm{mg}$ tab & $\checkmark$ & & & & & \\
\hline & Total & 6 & 15 & 5 & 14 & 5 & 12 \\
\hline \multirow{7}{*}{$\begin{array}{l}\text { Anti } \\
\text { Hipertensi }\end{array}$} & Ramipril $5 \mathrm{mg}$ tab & & & & & & \\
\hline & Ramipril $10 \mathrm{mg}$ tab & & $\checkmark$ & & $\checkmark$ & & $\checkmark$ \\
\hline & Spironolacton $25 \mathrm{mg}$ tab & & & & & $\checkmark$ & \\
\hline & $\begin{array}{l}\text { Spironolacton } 100 \mathrm{mg} \\
\text { tab }\end{array}$ & & $\checkmark$ & & $\checkmark$ & & $\checkmark$ \\
\hline & Tanapres $10 \mathrm{mg}$ tab & & & & & & \\
\hline & V-bloc $6,25 \mathrm{mg}$ tab & & & & & $\checkmark$ & \\
\hline & Total & 6 & 17 & 5 & 16 & 7 & 14 \\
\hline Anti Platelet & Aspilet $80 \mathrm{mg}$ tab & & & & & & \\
\hline
\end{tabular}




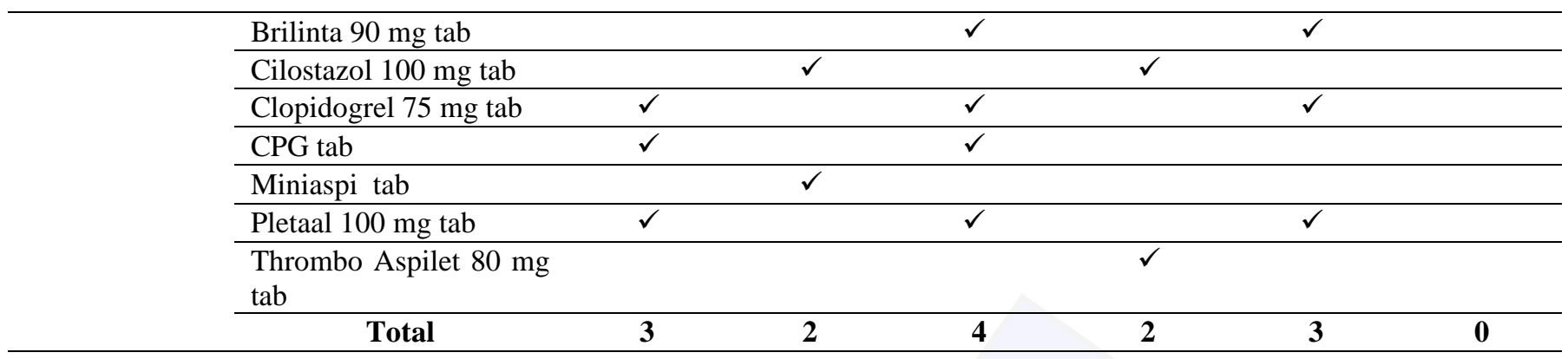

Pengelolaan obat merupakan siklus manajemen obat yang terdiri dari beberapa tahapan yaitu seleksi, perencanaan dan pengadaan, distribusi, dan pengguna (Sanjaya \& Hidayat, 2016). Mengingat ketidakefisien dan ketidaklancaran pengadaan obat, maka dapat memberikan dampak negatif terhadap rumah sakit pada kejadian stagnant dan stockout kelas terapi antihipertensi, sehingga rumah sakit perlu melakukan evaluasi terhadap pengadaan obat-obat tersebut. Hal ini bertujuan untuk mengetahui kelemahan dalam pelaksanaannya untuk dapat dilakukan upaya perbaikan dalam rangka meningkatkan pelayanan kesehatan kepada masyarakat (Cahya, 2016). Pengelolaan obat yang efisien mempengaruhi keberhasilan manajemen untuk menghindari perhitungan kebutuhan obat yang tidak akurat dan rasional. Tujuan pengelolaan obat ini untuk menjamin ketersediaan obat yang berkualitas yaitu tepat jenis, tepat jumlah, tepat waktu dan dana yang mencukupi sehingga dapat meningkatkan kualitas hidup pasien.

\section{Kesimpulan}

Kejadian stagnant dan stockout obat kardiovaskuler di instalasi farmasi rumah sakit menunjukkan bahwa jumlah tertinggi terdapat pada kelas terapi antihipertensi sebanyak 32 item dengan jumlah stagnant $12 \%$ dan jumlah stockout $31,3 \%$.

\section{Daftar Pustaka}

Ali, M. Y., Muttaqin, M., \& Syukur, A. T. (2017). Mutu Pelayanan Kesehatan Pos Pelayanan Terpadu (POSYANDU) Lanjut Usia (LANSIA) Di Kelurahan Tammua Kecamatan Tallo Kota Makasar. Jurnal Administrasi Negara, 23(1), 20-29.

Anas, S. (2008). Pengantar statistik pendidikan. Jakarta: Raja Grafindo Persada.
Anwar, T., \& Bahri. (2004). Dislipidemia Sebagai

Faktor Resiko Jantung Koroner. Fakultasa Kedokteran Sumatera Utara, January 2004, $1-10$.

Cahya, B. T. (2016a). carbon emission disclosure: ditinjau dari Media exposure, kinerja lingkungan dan karakteristik perusahaan. 66, 37-39.

Cahya, B. T. (2016b). carbon emission disclosure: ditinjau dari Media exposure, kinerja lingkungan dan karakteristik perusahaan. 05(02), 170-188.

Carolien, I., Fudholi, A., \& Endarti, D. (2017). Evaluasi Ketersediaan Obat Sebelum dan Sesudah Implementasi JKN pada Puskesmas di Kabupaten Keerom Provinsi Papua. $J$ Manaj Dan Pelayanan Farm, 7(1), 30-39.

Darnindro, N., \& Sarwono, J. (2017). Prevalensi Ketidakpatuhan Kunjungan Kontrol pada Pasien Hipertensi yang Berobat di Rumah Sakit Rujukan Primer dan Faktor-Faktor yang Memengaruhi. Jurnal Penyakit Dalam Indonesia, 4(3), 123-127.

Education, N. A., Heart, P. P. (National, Lung, \& Institute), B. (2003). Expert panel report: guidelines for the diagnosis and management of asthma: update on selected topics, 2002 (Issue 2). US Department of Health and Human Services, Public Health Service, National ....

Elvira, M., \& Anggraini, N. (2019). Faktor-Faktor Yang Berhubungan Dengan Kejadian Hipertensi. Jurnal Akademika Baiturrahim Jambi, $8(1), \quad 78$. https://doi.org/10.36565/jab.v8i1.105

Herlina, H. (2020). Evaluasi Ketersediaan Obat Terhadap Pengelolaan Sediaan Farmasi: Tinjauan Literatur. 
Huda, B., Kumala, S., \& Hasan, D. (2020). Analisis Ketersediaan Obat Antihipertensi Dan Pengaruhnya Terhadap Pengobatan Pasien Hipertensi Di Puskesmas Kota Bandar Lampung. Syntax Literate; Jurnal Ilmiah Indonesia, 5(6), 34-49.

Indonesia, K. K. R. (2014). InfoDATIN: Pusat Data dan Informasi Kementerian Kesehatan RI. Jakarta: Kementerian Kesehatan Republik Indonesia.

Indrawati, L., \& Tjandrarini, D. H. (2018). Peran indikator pelayanan kesehatan untuk meningkatkan nilai sub indeks kesehatan reproduksi dalam Indeks Pembangunan Kesehatan Masyarakat (IPKM). Media Penelitian Dan Pengembangan Kesehatan, 28(2), 95-102.

Kabi, G. Y. C. R., Tumewah, R., \& Kembuan, M. A. H. N. (2015). Gambaran faktor risiko pada penderita stroke iskemik yang dirawat inap neurologi RSUP Prof. Dr. RD Kandou Manado periode Juli 2012-Juni 2013. ECliniC, 3(1).

Karo, S. K. (2012). Hipertensi adalah Masalah Kesehatan Masyarakat. Dalam: Rilantono LI (Penyunting). "Penyakit Kardovaskular (PKV), 5, 235-248.

Laidahane, I. F. (2018). Manajemen Pengelolaan Obat di Instalasi Farmasi Rsud Lubuk Sikaping Kabupaten Pasaman. https://repository.unsri.ac.id/13260/2/RAMA _10011181320039_0910038601_000802780 1_01_front_ref.pdf

Lionetto, F., Pappadà, S., Buccoliero, G., Maffezzoli, A., Marszałek, Z., Sroka, R., Stencel, M., Buser, Y. M., Grouve, W. J. B., Vruggink, E., Sacchetti, F., Akkerman, R., Rudolf, R., Mitschang, P., Neitzel, M., Xu, X., Ji, H., Qiu, J., Cheng, J., Dhondt, M. C. (2020). Title. Composites Part A: Applied Science and Manufacturing, 68(1), 1-12. http://dx.doi.org/10.1016/j.ndteint.2014.07.00 1\%0Ahttps://doi.org/10.1016/j.ndteint.2017.1 2.003\%0Ahttp://dx.doi.org/10.1016/j.matdes. 2017.02.024
Mellen, R. C., \& Pudjirahardjo, W. J. (2013). Faktor Penyebab dan Kerugian Akibat Stockout dan Stagnant Obat di Unit Logistik RSU Haji Surabaya. Jurnal Administrasi Kesehatan Indonesia, 1(1), 99-107.

Pebrianti, P. (n.d.). Manajemen Logistik Pada Gudang Farmasi Rumah Sakit Umum Daerah Kabelota Kabupaten Donggala. Katalogis, 3(7).

Rangkuti, A. N. (2014). Metode Penelitian Pendidikan. Bandung: Citapustaka Media.

Ridwan, M., Yusni, \& Nurkhalis. (2020). Analisis Karakteristik Nyeri Dada Pada Pasien Sindroma Koroner Akut Di Rumah Sakit Umum Daerah Dr. Zainoel Abidin Banda Aceh. Journal of Medical Science, 1(1), 2126.

https://rsudza.acehprov.go.id/publikasi/index. php/JMS/article/view/5

Sanjaya, G. Y., \& Hidayat, A. W. (2016). Pemantauan Obat dan Perbekalan Kesehatan di Indonesia: Tantangan dan Pengembangannya. JURNAL MANAJEMEN DAN PELAYANAN FARMASI (Journal of Management and Pharmacy Practice), 6(2), 159-168.

Seto, S., Nita, Y., \& Triana, L. (2015). Manajemen Farmasi 2: Edisi 4: Lingkup apotek, farmasi rumah sakit, industri farmasi, pedagang besar farmasi. Airlangga University Press.

Siti Rohmatul Laily. (2017). Hubungan Karakteristik Penderita Dan Hipertensi Dengan Kejadian Stroke Iskemik. Jurnal Berkala Epidemiologi, 5(1), 48-59. https://doi.org/10.20473/jbe.v5i1.

Suciati, S. (2006). Analisis Perencanaaan Obat Berdasarkan ABC Indeks Kritis di Instalasi Farmasi. Juenal Manajemen Pelayanan Kesehatan, 09(01), 19-26.

Susilo Yekti, W. (2012). Cara Jitu Mengaatasi Hipertensi. Yogyakarta.

Yahya, A. F., \& Sp JP K, F. (2010). Menaklukkan Pembunuh No. 1: Mencegah dan Mengatasi Penyakit Jantung Koronenr Secara Tepat dan Cepat. 